\title{
REFERENCE UPPER-AIR OBSERVATIONS FOR \\ CLIMATE Rationale, Progress, and Plans
}

by Dian J. Seidel, Franz H. Berger, Howard J. Diamond, John Dykema, David Goodrich, Franz Immler, William Murray, Thomas Peterson, Douglas Sisterson, Michael Sommer, Peter Thorne, Holger Vömel, and Junhong Wang

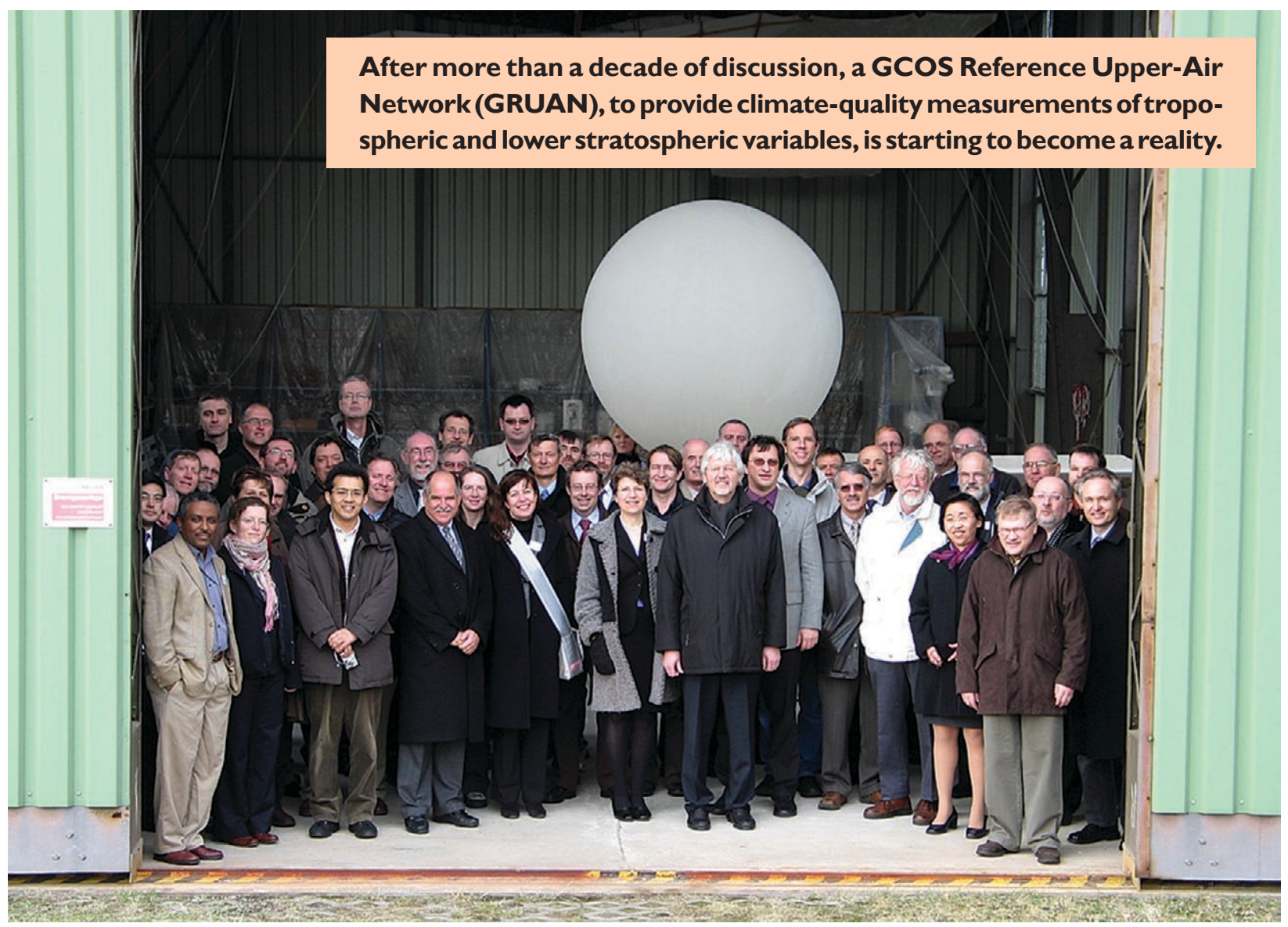

The Deutscher Wetterdienst's Meteorologisches Observatorium Lindenberg has been designated GRUAN Lead Center and is the first GRUAN network station. Here an inflated balloon for a 1200 UTC radiosonde observation is in the balloon shed, where participants at the GRUAN implementation workshop gathered in February 2008. In addition to upper-air soundings, the observatory also makes most of the GRUAN first and second priority observations.

$\mathrm{n}$ a recent commentary in Nature, Nisbet (2007) called environmental monitoring "science's Cinderella, unloved and poorly paid" and noted that sustained, long-term, ground-based measurements are underappreciated and underfunded because they are seen neither as basic measurements to test scientific hypotheses nor as challenging high-tech opportunities for profit by commercial interests. Upper-air observations for climate are a prime example of this problem and have never received the attention they deserve. Since the early 1990s, 
the climate research community has been calling for a ground-based reference observing system for measuring upper-air changes (Karl 1996; Karl et al. 2006; NRC 1999; Trenberth et al. 2002). Now, as plans for, and implementation of, the Global Climate Observing System (GCOS) have evolved (GCOS 2004), a GCOS Reference Upper-Air Network (GRUAN) has started to take shape. The purpose of this article is to concisely articulate the rationale for GRUAN, the progress to date, and future plans.

WHAT IS GRUAN? GRUAN is an international reference observing network, designed specifically to meet climate requirements and to fill a major void in the current global observing system. The key aspects of GRUAN have been developed through three work- shops. The first, held at the National Oceanic and Atmospheric Administration (NOAA) in Boulder, Colorado, in February 2005, identified the climate observation requirements of a reference upper-air network (Fig. 1). The second, held at the University of Washington in Seattle, Washington, in May 2006, explored potential technologies and networks that could meet the stated requirements. Details about these two workshops are reported by GCOS (2007). The third workshop, held at the Lindenberg Meteorological Observatory in Germany in February 2008 (Fig. 2), reached decisions on issues related to instrumentation, observing protocols, management, and relationships between GRUAN and other programs and organizations, all of which are needed to initiate the program (GCOS 2008).

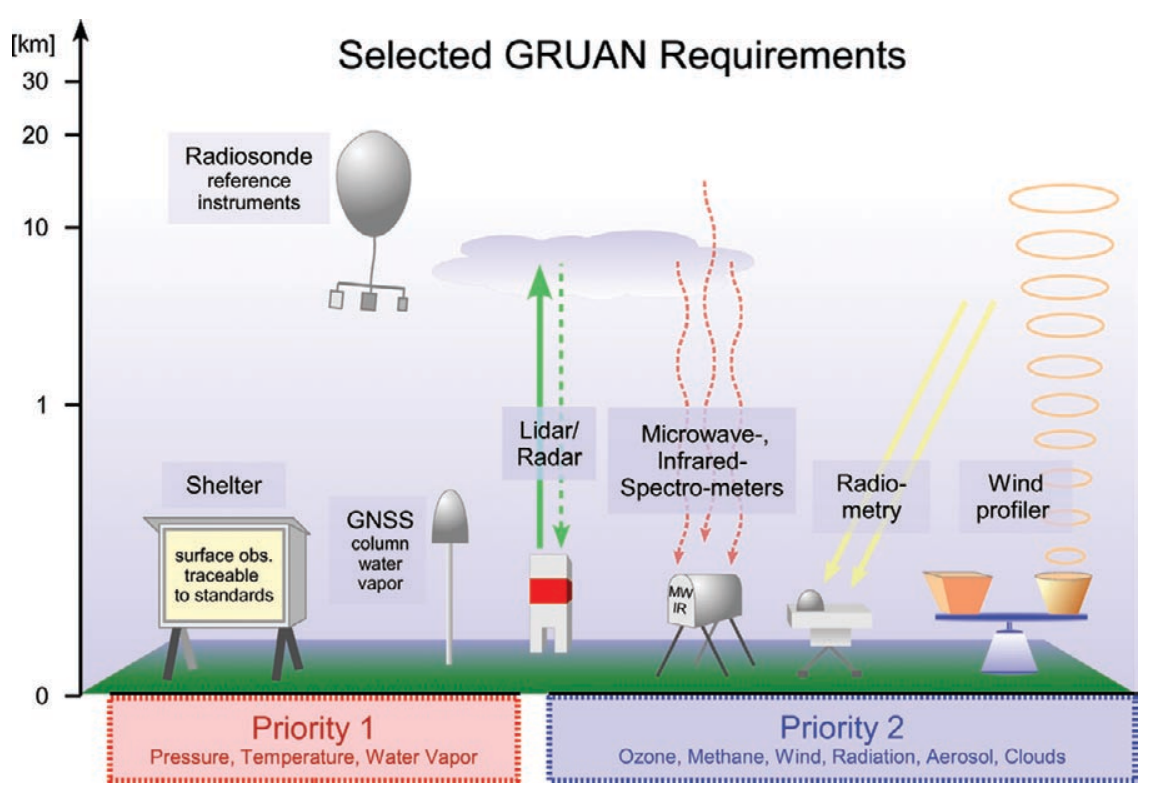

FIG. I. Schematic diagram showing some required measurements for a generic GRUAN station. The first priority includes surface and reference upper-air meteorological variables and total column water vapor from ground-based Global Navigation Satellite System (GNSS) receivers. The second priority includes wind profiles, surface radiation parameters (ideally as measured by the GCOS Baseline Surface Radiation Network), temperature and water vapor from a groundbased remote sensor such as a microwave or multichannel infrared radiometer, water vapor and cloud information

from ground-based lidar, and total column and profile measurements of ozone, methane, and aerosols. Third and fourth priority variables [not illustrated here; see GCOS (2007)] include carbon dioxide profiles and detailed cloud and hydrologic variables.

AFFILIATIONS: SEIDEL-NOAA/Air Resources Laboratory, Silver Spring, Maryland; Berger, Immler, SOMmer, ANd Vömel-Deutscher Wetterdienst, Meteorologisches Observatorium Lindenberg, Lindenberg, Germany; DIAMOND-NOAA/National Climatic Data Center/World Data Center for Meteorology, Silver Spring, Maryland; DYKEMA-School of Engineering and Applied Sciences, Harvard University, Cambridge, Massachusetts; GoODRICH*_ WMO/Global Climate Observing Programme, Geneva, Switzerland; MurRAY—STG, Inc., NOAA/Climate Program Office, Silver Spring, Maryland; Peterson - NOAA/National Climatic Data Center, Asheville, North Carolina; SISTERSON-Decision and Information Science Division, Argonne National Laboratory, Argonne, Illinois; THORNE-Met Office, Hadley Centre, Exeter, United Kingdom; WANG - National Center for Atmospheric Research, Earth
Observing Laboratory, Boulder, Colorado *CURRENT AFFILIATION: NOAA/Climate Program Office, Silver Spring, Maryland CORRESPONDING AUTHOR: Dian J. Seidel, NOAA Air Resources Laboratory, I3I5 East West Highway (R/ARL), Silver Spring, MD 20910

E-mail: dian.seidel@noaa.gov

The abstract for this article can be found in this issue, following the table of contents.

DOI:10.1175/2008BAMS2540.I

In final form 30 July 2008

(C2009 American Meteorological Society 
The resulting GRUAN will feature:

- A network of several dozen stations, made operational in a phased process, that serve primarily as a long-term anchor to other networks: GRUAN will not be globally complete but will sample major climatic regimes, latitudes, altitudes, and surface types. Each station will be associated with a host institution having the necessary scientific and technical expertise and a commitment to the long-term operation of the site.

- Adherence to the 10 GCOS climate monitoring principles agreed to by the United Nations Framework Convention on Climate Change (GCOS 2003): These set as priorities the quality and long-term continuity and homogeneity of the observations and metadata needed for their interpretation; the use of the data in research and assessments; the

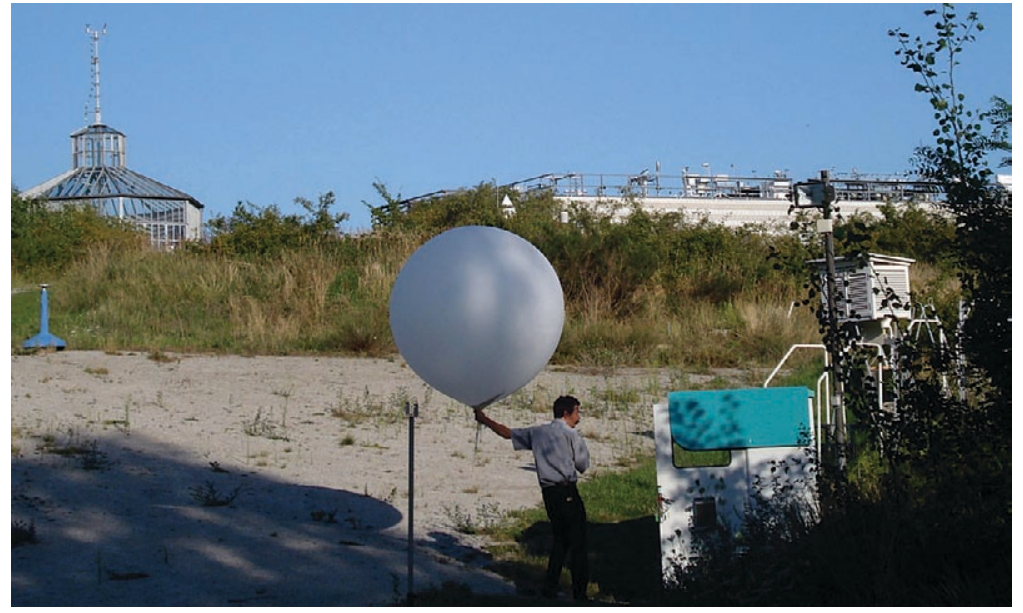

FIG. 2. The Deutscher Wetterdienst's Meteorologisches Observatorium Lindenberg, designated as GRUAN Lead Center and the first GRUAN network station, has all the GRUAN observational capabilities depicted in Fig. I. Here Michael Schröter prepares to launch a radiosonde and verifies that the ground station is receiving data from the sonde. A Stevenson shelter (behind bushes at lower right) houses reference surface instruments for comparison. On the roof of the radiation building (in background on right) are Baseline Surface Radiation Network instruments (pyranometer, pyrheliometer, pyrgeometer, and all-sky camera) and a microwave radiometer (far right). A GSNN antenna is to the left of the radiation building. The historic winch house (in background on left) was used in the nineteenth and twentieth centuries for meteorological profile observations with tethered aerological kites; the observatory holds the world record for achieving a kite altitude of $9,750 \mathrm{~m}$ on I Aug 1919.

establishment of requirements at the outset of system design and implementation; and data management systems that facilitate data access, among other things.

- Measurements of the "Essential Climate Variables" identified by GCOS (2003) with a focus on the highest priority upper-air variables, using highquality instruments to provide the most accurate data possible, as shown schematically in Fig. 1.

- Ongoing real-time and retrospective crossvalidation of different measurements of the same parameter and evaluation of measurement accuracies and drifts.

- A strong lead center providing scientific leadership and oversight, managing the network, training operators, and ensuring proper data archival and free dissemination: The Meteorological Observatory Lindenberg, Richard Aßmann Observatory, will serve as GRUAN Lead Center, based on the Deutscher Wetterdienst's offer of substantial financial, scientific, and technical support, in response to a call for interest issued by the GCOS Secretariat. Figure 2 illustrates some of the GRUAN-relevant instrumentation already in place at Lindenberg.
- A strong commitment to coordinate with other existing networks and observing systems and to provide scientifically robust service to the user community: Achieving coordination among networks is recognized to be a challenge but is seen as critical to the long-term success of GRUAN and other networks.

These concepts begin to trace the outlines of what GRUAN is and can be. It is also important to clearly articulate what GRUAN is not. It is not a set of identical stations; some will be more comprehensive than others, although all will make a core set of first priority observations (Fig. 1). It is not a replacement either for the existing radiosonde network, whose spatial density meets weather needs that GRUAN cannot, or for the GCOS Upper-Air Network (GUAN; GCOS 2002). Figure 3 schematically depicts a threetiered upper-air observing system architecture, with a $30-40$ station GRUAN network providing reference observations, that is, the long-term anchor points that comprehensively characterize the atmospheric column with the best measurements currently feasible. The base of the system is the complete 


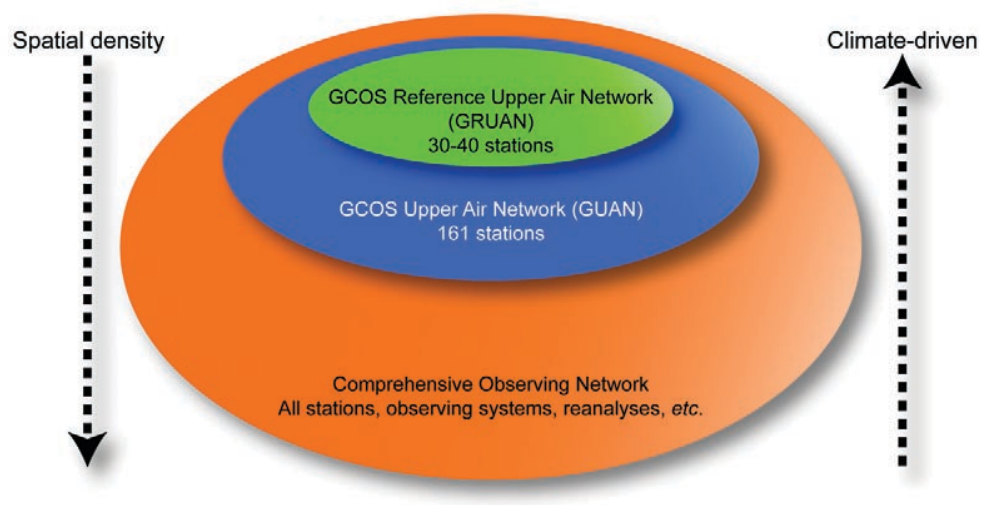

FIG. 3. Schematic diagram of the GCOS tiered-network concept of upper-air observations for climate. The GRUAN offers less spatial density than either the GUAN (a subset of the global radiosonde network stations that have made commitments of longevity and metadata collection) or the comprehensive network (which includes all ground-based and satellite upper-air observations and reanalyses). However, GRUAN is designed to directly address climate monitoring and science requirements by employing specialized instruments and adhering fully to established climate monitoring principles.
Climate researchers turned to observations from the global radiosonde network to evaluate satellite Microwave Sounding Unit observations, but frequent, and often undocumented, changes in radiosonde instruments and observing methods severely hampered the comparison of upper-air temperature trends (Gaffen 1994). Similarly, the satellite temperature record was also marred by time-varying biases (inhomogeneities) associated with a particular sensor on a single satellite and with the merging of data from consecutive satellite platforms.

Significant scientific capital has been expended over the past two decades in efforts to determine what observations of upper-air temperature can, and cannot, tell us about past changes in tropospheric global upper-air observing system, serving a wide variety of purposes, primarily weather prediction, and including the operational radiosonde network, aircraft and satellite observations, etc., and embracing model-assimilated upper-air datasets and reanalyses. The 161-station GUAN is a subset of the operational radiosonde network that in the late 1990s committed to long-term, consistent observations, but that do not deploy any special instruments for high-quality climate observations.

GRUAN is a key component of the GCOS, and GCOS in turn is the formal climate component of the Global Earth Observing System of Systems (GEOSS 2008). GRUAN contributes to the GEOSS goal of "understanding, assessing, predicting, mitigating, and adapting to climate variability and change" (GEO 2007). GRUAN is also a crucial element supporting the Global Space-Based Inter-Calibration System (GSICS; CGMS 2008; Ohring et al. 2007).

WHY DO WE NEED GRUAN? Reference upperair observations can serve a variety of scientific purposes, some of which are articulated by GCOS (2007). Here we highlight a few key needs that GRUAN is designed to meet.

Monitoring changes in temperature profile. Concern about apparent discrepancies between surface air temperature trends and tropospheric temperature trends as observed by satellites (NRC 2000) was an early motivation for a reference upper-air network. and stratospheric temperature. The issue has been addressed by the Intergovernmental Panel on Climate Change (Solomon et al. 2007), special panels convened by the National Academies (NRC 2000), the U.S. Climate Change Science Program (Karl et al. 2006), and dozens of research articles, and still has not been fully resolved. Current best estimates of temperature trends from research-quality satellite and radiosonde datasets have a wide range and for some regions do not even agree as to whether the atmosphere has warmed or cooled (Fig. 4). GRUAN will provide homogeneous in situ temperature profile data for monitoring local trends, for correlating temperature changes with changes in other parameters, and perhaps most significantly for adjusting satellite record biases so that long-term changes can be estimated globally with greater confidence.

Characterizing upper-air water vapor. For weather forecasting purposes, boundary layer and lowertropospheric humidity observations (or total column water vapor, which is dominated by the lower troposphere) are of prime interest. But for climate purposes, humidity in the upper troposphere and lower stratosphere (UTLS) is of equal importance (Held and Soden 2000). There the radiative, chemical, and microphysical roles of the water molecule assume primacy. The enhanced greenhouse effect of a given increase in water vapor in these regions is many times greater than in the lower troposphere. High clouds due to water vapor in the UTLS region affect 
both the planet's shortwave albedo and its longwave greenhouse effect, and both cloud particles and water molecules are involved in chemical reactions that govern stratospheric ozone concentrations.

Standard radiosonde humidity sensors have very poor response at the low temperatures, pressures, and water vapor concentrations of the UTLS region (Fig. 5). Currently, satellites and special researchquality instruments on aircraft and balloon platforms are the main sources of information on UTLS water vapor, and differences among these measurement systems have been difficult to reconcile (WCRP 2000; Randel et al. 2006; Scherer et al. 2008). Accurate measurement of water vapor from the surface to the lower stratosphere with observational uncertainty well quantified is a major thrust of GRUAN.

Interrelating atmospheric composition, radiation, and meteorological parameters. Model simulations of past climate change and predictions of future changes require accurate representation or parameterization of climate feedback processes, because these processes determine the sensitivity of the climate system to an imposed forcing, such as greenhouse gas increases. For example, changes in the vertical profile of ozone (due to changes in stratospheric concentrations of ozone-depleting substances and changes in tropospheric pollution) impact the shortwave and longwave radiation flux profiles, which in turn modify temperature, humidity, and cloud profiles, which feed back on ozone. Feedback processes such as this cannot be directly measured but must be constructed based on measurements of changes in correlated and interacting variables (NRC 2003). GRUAN addresses this by making collocated observations of meteorological, radiation, and atmospheric composition variables.

Ensuring comprehensive estimates of measurement error. One valuable lesson of the U.S. Department of Energy (DOE) Atmospheric Radiation Measurement (ARM) Climate Research Facility (ACRF; a DOE Office of Science national user facility) is the synergistic value of 1) measurements of a given variable by different, independent methods and 2) measurements of complementary variables that facilitate interpretation of a given variable (Tobin et al. 2006). GRUAN is committed to such an approach to identify measurement errors and constrain measurement uncertainty.

Providing a strong basis for satellite and radiosonde data calibration. GRUAN will not provide observations with the global coverage of satellites or even of the operational radiosonde network (including GUAN). Those systems, however, absolutely require reference observations to transform so-called environmental data records to climate data records. A primary distinction between these is the removal of time-varying biases that may be negligible for weather forecasting purposes but can be ruinous for detecting true long-

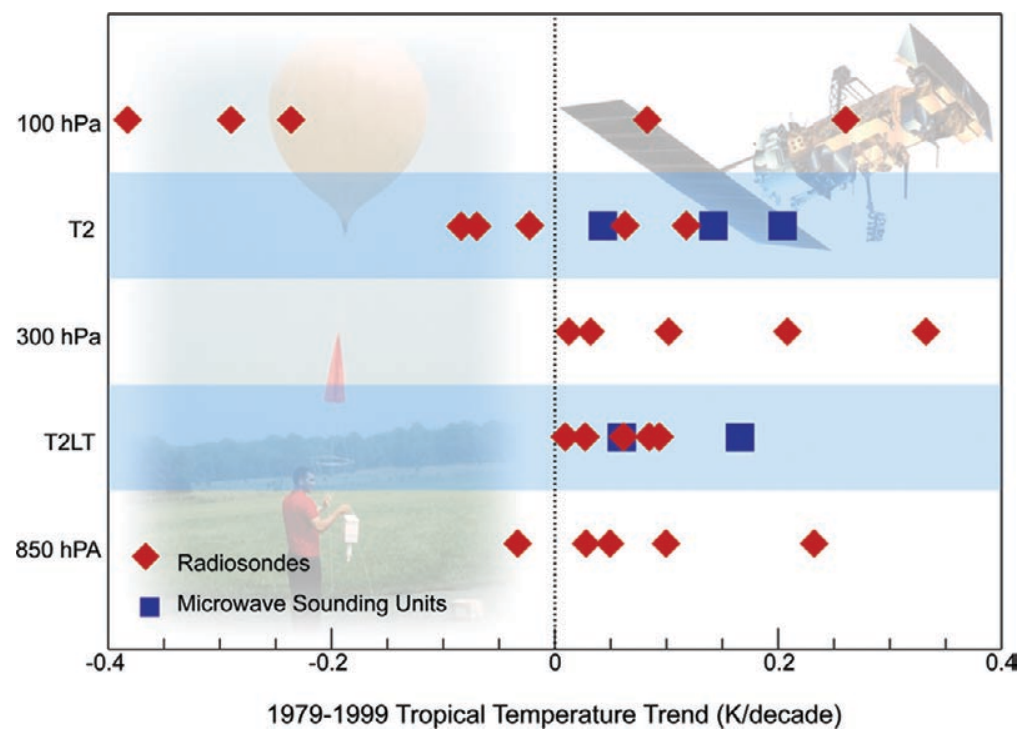

Fig. 4. Comparison of upper-air temperature trends for 1979-99 in the tropics for selected vertical levels and Microwave Sounding Unit (MSU) layers from a variety of research-quality datasets (adapted from Santer et al. 2008). Five radiosonde datasets, shown by diamonds, were produced by Thorne et al. (2005a), Free et al. (2005), Haimberger et al. (2008, two datasets), and Sherwood et al. (2008). MSU datasets, shown by squares, are from Mears and Wentz (2005), Christy et al. (2003), and Vinnikov et al. (2006). MSU layers represent averages over large depths of the atmosphere, whereas radiosondes are archived on standard pressure levels, and can be converted to MSU equivalents using weighting functions. The T2 layer is observed by the MSU and is a mainly tropospheric layer with some lower stratospheric influence. The T2LT layer is constructed to remove the stratospheric influence and focus on the lower troposphere. Note the large degree of structural uncertainty (Thorne et al. 2005b) inherent in these dataset construction efforts, which reference upperair observations are intended to mitigate. [(left) Radiosonde launch photo and (right) Polar Operational Environmental Satellite (POES) image provided by NOAA.] 


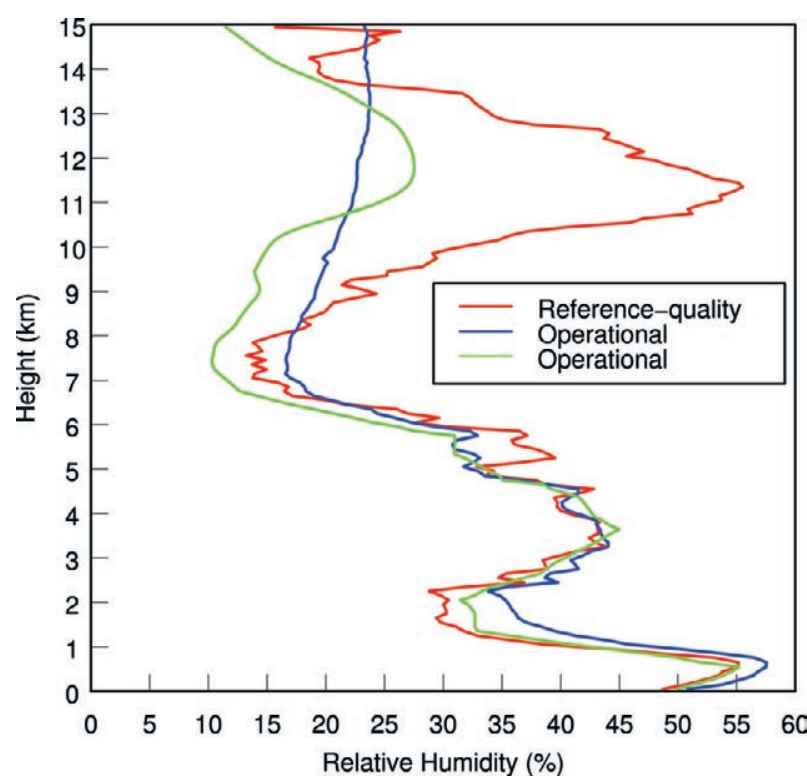

FIG. 5. Comparison of mean relative humidity profiles (averaged from six soundings at the Homestead research site, Oklahoma) measured by a referencequality humidity sensor (Snow White, red curve) and by two types of operational humidity sensors (carbon hygristor, blue curve; Vaisala RS80-H, green curve). Note the dry bias in the operational sensors, particularly in the upper troposphere, and the lack of response of the hygristor at heights above $7 \mathrm{~km}$. Adapted from Wang et al. (2003).

term climate change. The satellite community has strongly supported the establishment of long-term in situ reference upper-air observations for validation of satellite measurements and data products (Ohring 2007), and there is close liaison between GRUAN and GSICS planning activities. GSICS requirements for special, coordinated GRUAN observations for satellite calibration and validation and for long-term GRUAN data for homogenizing satellite data products will be fully integrated in GRUAN planning and operations. Vömel et al. (2007a) illustrate how reference-quality in situ water vapor measurements can be used to validate current satellite observations, and Taylor et al. (2008) describe how a suite of ground-based observations can be used to validate hyperspectral satellite soundings planned for the future.

Ensuring continuity of the climate record. Because of their high cost and technical complexity, satellite programs risk gaps in the observational record due to launch failures, instrument degradation, or budget shortfalls. For some measurements, such as solar irradiance measured from outside the Earth's atmosphere, such a gap might be impossible to fill, but for atmospheric profile observations, ground-based measurements can serve as a bridge if they are of sufficient accuracy, sampling density, and long-term continuity. GRUAN observations of atmospheric profiles, made with multiple, complementary techniques, will fill gaps in satellite records and serve as a transfer standard between satellite data segments.

In short, the main reasons for establishing GRUAN are to

- provide long-term high-quality upper-air climate records, with complete estimates of measurement error;

- constrain and adjust data from more spatially comprehensive global observing systems (including satellites and current radiosonde networks);

- fully characterize the properties of the atmospheric column and their changes; and

- ensure that potential gaps in satellite programs do not invalidate the long-term climate record.

\section{WHO WILL STEER, MANAGE, AND OPERATE GRUAN? The coordinated efforts of} many individuals and institutions are needed to ensure a successful GRUAN (GCOS 2008). GCOS provides direction and oversight through its Atmospheric Observation Panel for Climate (AOPC). The AOPC is responsible for several observing systems, and has established a Working Group on Atmospheric Reference Observations (WG-ARO) to provide direct guidance and oversight to GRUAN, with the support of the GCOS Secretariat in Geneva. Terms of reference and member rosters for both the AOPC and its WG-ARO are on the GCOS Web site (www.wmo.ch/ pages/prog/gcos/index.php? name=aopc).

Day-to-day management of GRUAN is the responsibility of the GRUAN Lead Center, now established at the Meteorological Observatory Lindenberg, with a dedicated staff of one visiting and three permanent scientists. Lead Center responsibilities include characterizing instrument error; cultivation and identification of instrument mentors to provide sitespecific guidance; training station staff; succession planning to ensure continuity of observations and expertise; coordination with the user community; network management; data archival, dissemination and potential reprocessing; and research using GRUAN data.

Operation of GRUAN sites is the responsibility of the site scientific and technical staff, who in most cases will be affiliated with the governmental or academic (or perhaps a private) institution hosting the site. They are responsible for operating and maintaining instruments, some aspects of data quality control, and 
working with the Lead Center. As GRUAN matures, these arrangements may be adjusted.

\section{WHERE WILL GRUAN STATIONS BE} LOCATED? Working with the dictum "[s]tart small, but start," GRUAN will begin operation at a single station, the Lead Center at Lindenberg. At the GRUAN initiation meeting, February 2008, a number of initial candidate sites, offering a rich variety of ground-based in situ, remote-sensing, and radiosonde capabilities, were identified. These were a mix of national observatories, research stations (including the U.S. DOE's ACRF sites in the North Slope of Alaska, the Southern Great Plains, and one or more of the three sites in the tropical western Pacific), and operational radiosonde sites. At the time of submission of this article, World Meteorological Organization (WMO) is initiating formal invitations to these sites. For current information on GRUAN network stations, the reader may refer to the GRUAN Web site (www.gruan.org).

WHAT OBSERVATIONS WILL BE MADE AT GRUAN SITES? A full description of GRUAN measurements is beyond the scope of this paper, in part because of the plethora of observations that might be available from a given site, and in part because some instrumentation plans are under development. As shown schematically in Fig. 1, all stations will be equipped to take, at minimum, the GRUAN first priority observations, including reference radiosonde observations of temperature, humidity, pressure, height, and wind; surface meteorological parameters; and total column water vapor using ground-based Global Navigational Satellite System (GNSS) receivers in combination with surface pressure observations. Highly desired, but not required, is the capacity for vertical profile observations using at least one ground-based remote-sensing technique. Second priority observations include total column and profile measurements of traces gases (ozone and methane) and aerosols, as well as cloud and radiation parameters. Ideally, a GRUAN site would also be a GCOS Baseline Surface Radiation Network site.

The exact design of a GRUAN reference radiosonde soon will be under study and field testing, in coordination with the WMO Commission on Instruments and Methods of Observation, which has a long history of field testing and intercomparison of radiosondes. The guiding principles are to use best available technology and to ensure that instrument error can be fully characterized by making redundant measurements of a given atmospheric variable, by calibrating sensors with references traceable to national metrology institutes whenever possible, and by following the International Organization for Standards guidelines for calculating and expressing uncertainty in measurements (ISO 1995).

For temperature and pressure observations, some combination of commercially available sensors appear to meet GRUAN specifications (GCOS 2007), particularly for nighttime soundings when solar radiation effects can be ignored. Reference humidity observations pose a greater challenge because no single commercially available instrument is responsive over the full dynamic range of values likely to be encountered from the surface into the troposphere and lower stratosphere. Instruments such as the Cryogenic Frostpoint Hygrometer (CFH; Vömel et al. 2007b), the Fluorescent Advanced Stratospheric Hygrometer for Balloon (FLASH-B) Lyman-alpha instrument, the Snow White chilled mirror hygrometer, or the Vaisala RS92 (Suortti et al. 2008) or RS-90 FN (Leiterer et al. 1997), may be used for reference measurements in their respective, valid altitude range. Other proven reference instruments may be introduced, with careful attention to data continuity concerns.

\section{HOW WILL GRUAN OBSERVATIONS BE ARCHIVED, DISSEMINATED, AND USED?}

Ensuring the early, ongoing, and widespread use of GRUAN observations is a GRUAN priority and the responsibility of the Lead Center. The importance of a committed GRUAN data center has been stressed from the outset, and a number of institutions are working together to ensure that existing data management capabilities and experience are available to GRUAN. These include the NOAA/National Climatic Data Center (NCDC), which also hosts World Data Center (WDC) for Meteorology-Asheville; the Global Observing Systems Information Center (see http://gosic.org); the data portal of the Network for the Detection of Atmospheric Composition Change (www.ndsc.ncep.noaa.gov/); the U.S. DOE ACRF archive and supporting infrastructure; and the Lead Center at Lindenberg.

It is expected that researchers from around the world will employ GRUAN data in a wide variety of studies. The AOPC Working Group on Atmospheric Reference Observations is encouraging research program managers to support projects that use GRUAN data to meet GRUAN goals, particularly those related to improving satellite data products, characterizing observational error, and understanding climate variations and change. 
WHEN WILL GRUAN MEASUREMENTS END? The GRUAN is explicitly a long-term measurement program for climate. GRUAN observations should continue as long as there is a clear need for in situ reference atmospheric profile observations for climate. We envision such a need to continue for at least the next several decades. Until satellite observations (or observations from any future systems) can be independently and unambiguously calibrated to international standards, ground-based profile measurements will be required to ensure a homogeneous and continuous climate record. GRUAN now stands ready to meet that need.

\section{HOW CAN INDIVIDUALS AND INSTI-} TUTIONS PARTICIPATE IN GRUAN? The GRUAN is just beginning to be realized. Its success and continuity will depend to a large measure on the involvement of the international scientific community. Constructive feedback and responses to this article, and expressions of interest in hosting and providing long-term support for a potential GRUAN site or engaging in GRUAN in other ways, are most welcome and should be directed to the director of the GRUAN Lead Center, the chair of the AOPC Working Group on Atmospheric Reference Observations, and the GCOS director. They can be contacted jointly via e-mail at gruan.chairs@dwd.de.

ACKNOWLEDGMENTS. We thank Jim Angell and Kirk Clawson (NOAA), David Parker (Met Office), and an anonymous referee for constructive reviews of this manuscript. NOAA, GCOS, and Deutscher Wetterdienst provided support for GRUAN workshops. Stephanie Lorenz (GCOS Secretariat) assisted in preparing the references, and Deborah Riddle (NOAA) helped in drafting figures. PWT was supported by the Joint Defra and MoD Programme, (Defra) GA01101 (MoD) CBC/2B/0417_Annex C5.

\section{REFERENCES}

CGMS, cited 2008: Global Space-Based Inter-Calibration System (GSICS) Implementation Plan. [Available online at www.star.nesdis.noaa.gov/smcd/spb/ calibration/icvs/GSICS/documents/SAT_GSICS_ Implement_plan.pdf.]

Christy, J. R., and Coauthors, 2003: Error estimates of version 5.0 of MSU-AMSU bulk atmospheric temperatures. J. Atmos. Oceanic Technol., 20, 613-629.

Free, M., and Coauthors, 2005: Radiosonde Atmospheric Temperature Products for Assessing Climate (RATPAC): A new data set of large-area anomaly time series. J. Geophys. Res. Atmos., 110, D22101, doi:10.1029/2005JD006169.

Gaffen, D. J., 1994: Temporal inhomogeneities in radiosonde temperature records. J. Geophys. Res., 99, 3667-3676.

GCOS, 2002: Guide to the GCOS Surface and Upper-Air Networks: GSN and GUAN. Version 1.1, GCOS-73, WMO Tech. Doc. 1106, 37 pp. [Available online at www.wmo.int/pages/prog/gcos/Publications/gcos73.pdf.]

- 2003: The second report on the adequacy of the Global Observing Systems for Climate in support of the UNFCCC. GCOS-82, WMO Tech. Doc. 1143, 85 pp. [Available online at www.wmo.int/pages/prog/ gcos/Publications/gcos-82_2AR.pdf.]

_ 2004: Implementation plan for the Global Observing System for Climate in support of the UNFCCC. GCOS-92, WMO Tech. Doc. 1219, 151 pp.

— , 2007: GCOS Reference Upper-Air Network (GRUAN): Justification, requirements, siting and instrumentation options. GCOS-112, WMO Tech. Doc. 1379, 42 pp. [Available online at www.wmo.int/ pages/prog/gcos/Publications/gcos-92_GIP.pdf.]

—, 2008: Report of the GCOS Reference Upper-Air Network Implementation Meeting, Lindenberg, Germany, 26-28 February 2008. GCOS-121, WMO Tech. Doc. 1435, 49 pp. [Available online at www.wmo. int/pages/prog/gcos/Publications/gcos-121.pdf.]

GEO, 2007: The Full Picture. Tudor Rose, 279 pp.

GEOSS, cited 2008: 10-year implementation plan, as adopted 16 February 2005. [Available online at http:// earthobservations.org.]

Haimberger, L., C. Tavolato, and S. Sperka, 2008: Toward elimination of the warm bias in historic radiosonde temperature records-Some new results from a comprehensive intercomparison of upper-air data. J. Climate, 21, 4587-4606.

Held, I. M., and B. J. Soden, 2000: Water vapor feedback and global warming. Ann. Rev. Energy Environ., 25, 441-475.

ISO, 1995: Guide to the Expression of Uncertainty in Measurement. International Organization for Standardization, $112 \mathrm{pp}$.

Karl, T. R., Ed., 1996: Long-Term Climate Monitoring by the Global Climate Observing System (GCOS): International Meeting of Experts, Asheville, North Carolina, U.S.A., January 9-11, 1995. Kluwer Academic Publishers, 518 pp.

—, S. Hassol, C. Miller, and W. Murray, Eds., 2006: Temperature Trends in the Lower Atmosphere: Steps for Understanding and Reconciling Differences. U.S. Climate Change Science Program, Synthesis and Assessment Report 1.1, 164 pp. 
Leiterer, U., H. Dier, and T. Naebert, 1997: Improvements in radiosonde humidity profiles using RS80/ RS90 radiosondes of Vaisala. Contrib. Atmos. Phys., 70, 319-336.

Mears, C. A., and F. J. Wentz, 2005: The effect of diurnal correction on satellite-derived lower tropospheric temperature. Science, 209, 1548-1551.

Nisbet, E., 2007: Cinderella science. Nature, 450, 789-790.

NRC, 1999: Adequacy of Climate Observing Systems. National Academy Press, 51 pp.

_ 2000: Reconciling Observations of Global Temperature Change. National Academies Press, 104 pp.

_ , 2003: Understanding Climate Change Feedbacks. Board on Atmospheric Sciences and Climate, National Academies Press, 166 pp.

Ohring, G., Ed., 2007: Achieving satellite instrument calibration for climate change. Workshop report, 152 pp. [Available online at www.orbit.nesdis.noaa. gov/star/documents/ASIC3-071218-webversfinal. pdf.]

— , and Coauthors, 2007: Achieving satellite instrument calibration for climate change. Eos, Trans. Amer. Geophys. Union, 88, doi:10.1029/2007EO110015.

Randel, W. J., F. Wu, H. Vömel, G. E. Nedoluha, and P. Forster, 2006: Decreases in stratospheric water vapor after 2001: Links to changes in the tropical tropopause and the Brewer-Dobson circulation. J. Geophys. Res., 111, D12312, doi:10.1029/2005JD006744.

Santer, B. D., and Coauthors, 2008: Consistency of modeled and observed temperature trends in the tropical troposphere. Int. J. Climatol., 28, 1703-1722, doi:10.1002/joc.1756.

Scherer, M., H. Vömel, S. Fueglistaler, S. J. Oltmans, and J. Staehelin, 2008: Trends and variability of midlatitude stratospheric water vapour deduced from the re-evaluated Boulder balloon series and HALOE. Atmos. Chem. Phys., 8, 1391-1402.

Sherwood, S. C., C. L. Meyer, R. J. Allen, and H. A. Titchner, 2008: Robust tropospheric warming revealed by iteratively homogenized radiosonde data. J. Climate, 21, 5336-5352.

Solomon, S., D. Qin, M. Manning, Z. Chen, M. Marquis, K. B. Averyt, M. Tignor, and H. L. Miller, Eds., 2007: Climate Change 2007: The Physical Science Basis. Cambridge University Press, 996 pp.

Suortti, T. M., and Coauthors, 2008: Tropospheric comparisons of Vaisala radiosondes and balloon-borne frost-point and Lyman-a hygrometers during the LAUTLOS-WAVVAP experiment. J. Atmos. Oceanic Technol., 25, 149-166.
Taylor, J. P., and Coauthors, 2008: EAQUATE: An international experiment for hyperspectral atmospheric sounding validation. Bull. Amer. Meteor. Soc., 89, 203-218.

Thorne, P. W., D. E. Parker, S. F. B. Tett, P. D. Jones, M. McCarthy, H. Coleman, and P. Brohan, 2005a: Revisiting radiosonde upper air temperatures from 1958 to 2002. J. Geophys. Res., 110, D18105, doi:10.1029/2004JD005753.

,-- , J. R. Christy, and C. A. Mears, 2005b: Uncertainties in climate trends: Lessons from upperair temperature trends. Bull. Amer. Meteor. Soc., 86, 1437-1443.

Tobin, D. C., and Coauthors, 2006: Atmospheric Radiation Measurement site atmospheric state best estimates for Atmospheric Infrared Sounder temperature and water vapor retrieval validation. J. Geophys. Res., 111, D09S14, doi:10.1029/2005JD006103.

Trenberth, K. E., T. R. Karl, and T. W. Spence, 2002: The need for a systems approach to climate observations. Bull. Amer. Meteor. Soc., 83, 1558-1559.

Vinnikov, K. Y., N. C. Grody, A. Robock, R. J. Stouffer, P. D. Jones, and M. D. Goldberg, 2006: Temperature trends at the surface and in the troposphere. J. Geophys. Res., 111, D03106, doi:10.1029/2005JD006392.

Vömel, H., and Coauthors, 2007a: Validation of Aura Microwave Limb Sounder water vapor by balloon-borne cryogenic frost point hygrometer measurements. J. Geophys. Res., 112, D24S37, doi:10.1029/2007JD008698.

— D. E. David, and K. Smith, 2007b: Accuracy of tropospheric and stratospheric water vapor measurements by the cryogenic frost point hygrometer: Instrumental details and observations. J. Geophys. Res., 112, D08305, doi:10.1029/2006JD007224.

Wang, J., D. J. Carlson, D. B. Parsons, T. F. Hock, D. Lauritsen, H. L. Cole, K. Beierle, and E. Chamberlain, 2003: Performance of operational radiosonde humidity sensors in direct comparison with a chilled mirror dew-point hygrometer and its climate implication. Geophys. Res. Lett., 30, 1860, doi:10.1029/2003GL016985.

WCRP, 2000: SPARC Assessment of Upper Tropospheric and Stratospheric Water Vapor. WCRP-113, WMO Tech. Doc. 1043, SPARC Rep. 2, 324 pp. [Available online at www.atmosp.physics.utoronto.ca/SPARC/ WavasComplet.pdf.] 